http:/ / dx.doi.org/10.5007/1982-5153.2015v8n1p131

\title{
Formação Reflexiva de Professores de Ciências e Enfoque Ciência, Tecnologia e Sociedade: Possíveis Aproximações
} (Reflective Education of Science Teachers and Focus on Science, Technology and Society: Possible Approaches)

\section{PRISCILA FRANCO BINATTO, DAISI TERESINHA CHAPANI A ANA CRISTINA SANTOS DUARTE}

Universidade Estadual do Sudoeste da Bahia (UESB) (priscilabinatto@yahoo.com, dt.chapani@gmail.com, tinaduarte2@gmail.com)

Resumo. O objetivo desse ensaio é discutir a orientação dos pressupostos teóricos do enfoque Ciência, Tecnologia e Sociedade (CTS) para a formação reflexiva de professores, visando identificar aproximações entre essas correntes teóricas, bem como as possíveis contribuições para a formação de professores de Ciências. Assim, iniciamos apresentando brevemente algumas abordagens do enfoque CTS no ensino, bem como as diferentes tradições do conceito de reflexão na formação de professores, estabelecendo relações entre essas e os modelos de formação docente. Concluímos, apontando aspectos que favorecem aproximações entre o enfoque CTS e a formação reflexiva de professores, como a relevância das dimensões sociais e políticas, a tendência democrática e emancipatória, a relevância dos aspectos conceituais e a prática social.

Abstract. The purpose of this essay is to discuss the orientation of the theoretical assumptions of the Science, Technology and Society (STS) approach for reflective teacher education, identifying similarities between these theoretical perspectives, as well as possible contributions to the science teachers' education. Thus, we begin by briefly presenting some STS focus approaches on education, and the different traditions of the concept of reflection in teacher education, connecting between those traditions and the models of teacher education. We conclude by pointing aspects that enhance approaches between the CTS focus and reflective teacher training, as well as the relevance of social and political dimensions, the democratic and emancipatory trend, the relevance of the conceptual aspects and the social practice.

Palavras-chave: enfoque CTS, formação reflexiva, professores de ciências

Keyword: STS studies, reflexive education, science teachers

\section{Introdução}

Atualmente, convivemos com o dinâmico e acelerado desenvolvimento científico e tecnológico que permeia e acaba até mesmo por ditar os rumos das nossas vidas. Esse desenvolvimento tem trazido inúmeros benefícios, mas não há como negar que trouxe também diversas consequências negativas, como o agravamento de questões ambientais, o consumo exacerbado e o uso do aparato científico e tecnológico de forma destrutiva e para a conquista do poder.

Reconhecendo o avanço e as possibilidades do uso da Ciência e Tecnologia (C\&T) pela sociedade, Silveira et al. (2010) enfatizam a necessidade de fomentar a reflexão crítica e a criação de espaços de participação popular nas decisões que envolvem o uso que se faz da C\&T.

Nesse contexto, evidencia-se o papel da escola, em especial do ensino de Ciências, em colaborar com a formação para o exercício da democracia, trazendo discussões que favoreçam uma visão mais realista da C\&T como produto social, fruto 
da construção humana sendo, portanto, permeada por valores e contextualizada historicamente.

Mas, se levarmos em conta o contexto brasileiro marcado por desigualdades sociais e pela exclusão da participação popular nas políticas de C\&T, concordamos com Auler e Bazzo (2001) que, para uma participação mais qualificada da sociedade, além da compreensão de conhecimentos científicos e tecnológicos, necessitamos também de iniciar a construção de uma cultura de participação.

Cabe refletir sobre o papel dos professores na construção desta cultura, tendo em vista que esses são frequentemente alijados dos processos decisórios da educação. Uma formação baseada na racionalidade técnica apresenta pouca possibilidade de problematizar as concepções estereotipadas de Ciência, trazidas pelos professores ou futuros professores para os espaços formativos, de modo que frequentemente estes as veem como uma série de verdades e conceitos a ser transmitida aos alunos ou ainda como um conjunto de técnicas e procedimentos de pesquisa e não como construção humana, social e histórica (FERRAZ, 2009).

Diversos autores questionam a persistência de uma lógica positivista, fundamentada na racionalidade técnica na formação dos professores para a área de Ciências (DEMO, 2010; CHAPANI, 2010; MEGID NETO; JACOBUCCI; JACOBUCCI, 2007; TEIXEIRA, 2003).

Corroborando com o exposto acima, Filho et al. (2013), ao investigarem as concepções de C\&T de professores de Ciências em exercício, identificaram a existência de crenças e atitudes ingênuas e distorcidas em relação à natureza da Ciência e Tecnologia. Os referidos autores relacionam essas crenças ao:

\footnotetext{
modelo de ensino ainda dominante na maioria das universidades (apesar das mudanças propostas nas legislações de ensino), que é pautado pelo positivismo lógico (objetividade, verdade, certeza, etc.) em detrimento de uma educação mais humana, cujos aportes estão em disciplinas das áreas da filosofia, história, sociologia, excluídas dos currículos de Ciências (p. 327).
}

Sendo assim, é importante refletir sobre as ações formativas de professores dessa área, na busca de uma mudança epistemológica que contribua para alargar a compreensão dos docentes sobre a natureza do conhecimento (CHAPANI, 2010).

Essa discussão leva-nos a questionar que subsídios teóricos poderiam dar sustentação para pensar no ensino de Ciências como possibilidade para uma sociedade capaz de tomar decisões e participar mais ativamente de forma justa e igualitária? Como favorecer uma imagem mais aproximada da Ciência, como construção social, se ainda 
FORMAÇÃO REFLEXIVA DE PROFESSORES DE CIÊNCIAS...

prevalecem concepções estereotipadas e marcadamente positivistas? Que referenciais poderiam orientar a formação inicial e continuada de professores na busca desses objetivos?

Alguns trabalhos apontam contribuições dos referenciais teóricos do enfoque CTS no ensino de Ciências para a formação de professores dessa área, o que indica um caminho de possibilidades. Martínez (2010), por exemplo, em sua tese de doutorado identificou, a partir da análise de discurso crítica de uma ação formativa com professores em exercício, as seguintes contribuições da perspectiva CTS para a formação docente: a problematização da ideologia tecnicista do currículo tradicional, a compreensão de autonomia docente e o favorecimento das interações dialógicas entre os integrantes do grupo investigado.

Cassiani e Linsingen (2009) investigaram uma proposta de estágio envolvendo o enfoque CTS crítico através de uma perspectiva discursiva, na formação de professores de Ciências. Segundo esses autores, o enfoque CTS fomentou nos futuros professores a reflexão sobre os sentidos de ensinar Ciências, bem como a relevância da natureza da Ciência no ensino. Outra contribuição importante foi a percepção, por parte dos envolvidos, de que as resistências dos estudantes nos processos de ensino-aprendizagem não se dão apenas pelas dificuldades internas à escola e sala de aula, mas por questões mais amplas de cunho político, social e econômico.

Soares (2012), também investigando uma proposta de estágio que buscou, entre outros suportes teóricos, o enfoque CTS e o referencial do professor como intelectual transformador, apresenta resultados semelhantes ao indicar que o trabalho a partir de uma perspectiva CTS possibilitou nos alunos participantes uma maior preocupação em abordar questões científicas e tecnológicas de forma mais humanística. Considerou ainda o desenvolvimento da dimensão crítica e formação para cidadania, por levarem em conta, aspectos como "responsabilidade social, ética, política, direitos, acessos, ações, valores humanos, dentre outros" (p. 148).

Porém, apesar das possibilidades que os referenciais do enfoque CTS podem trazer para a formação de professores, Azevedo et al. (2013) destacam que existem questões teóricas-epistemológicas e éticas que têm dificultado a apropriação desse enfoque pelas instituições de ensino. No levantamento realizado pelos referidos autores, eles identificaram que as instâncias formativas pouco têm contribuído para que os professores de Ciências superem visões ingênuas de C\&T, além de não favorecer a responsabilidade social dos docentes no compromisso de construção da cidadania. 
A partir das relações já apresentadas, no presente trabalho, temos como objetivo discutir a orientação dos pressupostos teóricos do enfoque CTS no ensino de Ciências e do professor reflexivo identificando as aproximações entre essas correntes teóricas, bem como as possíveis contribuições para a formação de professores de Ciências. Porém, dada a diversidade de interpretações e usos desses referenciais, cabe conceituar e caracterizar a quais abordagens estamos nos referindo.

\section{Definindo o enfoque CTS no ensino de Ciências}

Entre as décadas de 60 a 70, emergiu o Movimento Ciência, Tecnologia e Sociedade $(\mathrm{CTS})^{1}$. De acordo com Osorio (2002), desde sua origem, esse Movimento questiona a natureza social do conhecimento científico e tecnológico, bem como seu impacto sobre a situação econômica, social, aspectos ambientais e culturais das sociedades ocidentais. No campo da educação, o Movimento CTS, fundamenta-se na premissa de que democratizar a avaliação e o controle social do desenvolvimento científico e tecnológico é um compromisso básico de todos (LINSINGEN, 2007).

A implementação dos pressupostos do Movimento CTS no ensino, está relacionada à tentativa de superar a visão deformada da Ciência e Tecnologia como atividades autônomas, neutras e isoladas de outros contextos (ROEHRIG; CAMARGO, 2013; MARTÍNEZ; LOZANO, 2013).

De forma geral, podemos caracterizar o enfoque CTS como uma perspectiva que pretende favorecer a interseção de propósitos entre o ensino de Ciências, educação tecnológica e para a cidadania, em que os conteúdos científicos e tecnológicos são discutidos em uma abordagem integrada com seus aspectos históricos, éticos, políticos, ambientais e socioeconômicos (SANTOS, 2012; ACEVEDO DÍAZ et al. 2001; LUJÁN LÓPEZ; CEREZO, 2000).

Nessa perspectiva, o enfoque CTS objetiva a promoção da educação científica a partir da compreensão das inter-relações entre Ciência, Tecnologia e Sociedade, desenvolvendo a capacidade de tomada de decisão, a aprendizagem de conceitos científicos, além da formação de valores aliados com o compromisso de construção de uma sociedade mais justa e igualitária (SANTOS, 2012; 2011; TEIXEIRA, 2003). A partir desse entendimento, a problematização do impacto ambiental, resultante do

\footnotetext{
${ }^{1}$ Consideramos as diferenças de terminologia apontadas por STRIEDER (2012) em que o "Movimento CTS" é utilizado para indicar as discussões CTS em um contexto mais amplo. "Enfoque CTS" refere-se à inserção dos pressupostos do Movimento no campo educacional. Por fim, "Abordagens" CTS representam as diferentes maneiras de abordar as relações CTS no ensino de Ciências.
} 
próprio desenvolvimento científico e tecnológico, deve ser fomentada a fim de propiciar um repensar de valores e atitudes em busca de alternativas que minimizem esses impactos, revendo os processos de produção e hábitos de consumo exacerbado.

Entender C\&T como produtos culturais, fruto da interação humana, permeada por interesses e valores, nos favorece deixar de caracterizá-las como atividades autônomas e independentes da sociedade. Com efeito, voltamo-nos para a necessidade de compreendê-las minimamente, para que possamos opinar e decidir, tendo em vista a sociedade que queremos. É neste aspecto que a escola, buscando a inserção social e preparação de cidadãos assume um papel de suma importância.

Cabe questionar se esse entendimento é consenso nos trabalhos que se referenciam pelo enfoque CTS. Strieder (2008) em revisão bibliográfica sobre o uso dos referenciais do enfoque CTS no ensino de Ciências apontou que, o Movimento CTS tem, desde a origem, um caráter político e social, tendo como objetivo a busca pela participação da sociedade nas políticas e atividades envolvendo C\&T. Mas, a repercussão para a área educacional derivou em uma infinidade de aspectos e diferentes compressões.

Vale apresentar, portanto, algumas classificações que trazem a tona essas diferentes abordagens. Assim, o quadro abaixo, construído a partir das contribuições de Santos $(2012 ; 2011)$, apresenta uma breve síntese das classificações mais usadas em trabalhos com enfoque CTS.

Quadro 1 - Principais abordagens CTS

\begin{tabular}{|c|c|}
\hline $\begin{array}{c}\text { Classificação } \\
\text { de } \\
\text { Aikenhead } \\
(1994)\end{array}$ & $\begin{array}{l}\text { Classifica as abordagens de CTS em oito categorias, levando em conta a ênfase que } \\
\text { atribuem às inter-relações dos elementos da tríade e a polarização entre o ensino de } \\
\text { Ciências Naturais, foco dos primeiros níveis e o ensino de Ciências Humanas, destaque } \\
\text { dos últimos níveis. O primeiro nível é centrado nos conceitos científicos, sendo que o } \\
\text { enfoque CTS é eventual e visa motivar o aluno; enquanto que o último nível tem como } \\
\text { foco os estudos das inter-relações CTS em uma perspectiva sociológica, sendo o } \\
\text { conteúdo científico propriamente dito apresentado de maneira complementar. }\end{array}$ \\
\hline $\begin{array}{l}\text { Classificação } \\
\text { de Luján } \\
\text { López e } \\
\text { Cerezo } \\
(2000)\end{array}$ & $\begin{array}{l}\text { Dividida em três categorias: Enxerto CTS; Ciência vista por meio de CTS; e Programa } \\
\text { CTS puro. Na primeira categoria, os temas CTS têm importância secundária e são } \\
\text { incluídos sem alterar a abordagem tradicional dos conteúdos científicos. Na segunda os } \\
\text { conceitos científicos são introduzidos a partir dos temas CTS, que recebem destaque no } \\
\text { currículo. Já na terceira categoria, as discussões das implicações CTS são foco central } \\
\text { do programa e os conceitos científicos surgem de maneira complementar. }\end{array}$ \\
\hline $\begin{array}{l}\text { Classificação } \\
\text { de Auler e } \\
\text { Delizoicov } \\
\quad(2001)\end{array}$ & $\begin{array}{l}\text { Apresenta a visão reducionista e a ampliada. A visão reducionista é marcada por } \\
\text { reproduzir uma ênfase na concepção da neutralidade das decisões em C\&T, de forma a } \\
\text { contribuir para a consolidação dos mitos da superioridade do modelo de decisões } \\
\text { tecnocráticas, da perspectiva salvacionista da C\&T e do determinismo tecnológico. Ao } \\
\text { contrário, a visão ampliada busca a compreensão das interações entre CTS, na }\end{array}$ \\
\hline
\end{tabular}

\footnotetext{
${ }^{2}$ Auler e Delizoicov (2001) propõem essa classificação em relação à alfabetização científica e tecnológica. Porém, resolvemos manter o mesmo entendimento proposto por Santos $(2011,2012)$ de considerá-la também para o enfoque CTS.
} 
perspectiva de problematização desses mitos e da compreensão da existência de construções subjacentes à produção do conhecimento científico-tecnológico, o que em outras palavras significa uma análise crítica ao atual modelo de desenvolvimento econômico.

Fonte: Adaptado de texto de Santos $(2011,2012)$.

Ao analisarmos o quadro 01 constatamos que nem todas as abordagens têm a preocupação política destacada por Strieder (2008) como marca característica do Movimento CTS. Assim, apenas as últimas categorias de Aikenhead (1994), a Ciência vista por meio de CTS e programa CTS puro (LUJÁN LOPES; CEREZO, 2000) e a perspectiva ampliada de Auler e Delizoicov (2001) estariam vinculadas a um enfoque CTS crítico, tal como defende Santos (2007).

Existem também algumas diferenças entre as formas de organização dessas categorias. As primeiras, de Aikenhead (1994) e Luján Lopes e Cerezo (2000), estão mais voltadas para a forma de organização estrutural do currículo em torno das interrelações CTS e revelam apenas em algumas categorias a profundidade de análise e problematização dos conteúdos. Por outro lado, a classificação de Auler e Delizoicov (2001) tem preocupação maior na diferenciação por seu conteúdo político, centrando-se nas complexas relações, dimensões e interesses que permeiam as decisões científicas e tecnológicas.

A perspectiva ampliada é defendida por Auler e Delizoicov (2001), em detrimento da reducionista, por sua intenção em desvelar três mitos que permeiam as concepções de professores de Ciências: i) Mito da Superioridade do Modelo de Decisões Tecnocráticas, baseado no cientificismo, sustenta que apenas os especialistas poderiam solucionar os problemas sociais de um modo eficiente e ideologicamente neutro, eliminando a participação da sociedade nas decisões relacionadas à C\&T; ii) Mito da Perspectiva Salvacionista da Ciência e Tecnologia, ou seja, a Ciência e a Tecnologia entendidas como as únicas e melhores alternativas para resolver os problemas hoje existentes, visando sempre o bem-estar social; iii) Mito do Determinismo Tecnológico sustentado pela ideia de que a tecnologia define os limites do que a sociedade pode fazer, sendo autônoma e independente das influências sociais, caminhando em direção única e irreversível ao futuro e ao progresso.

Assim, a partir da visão ampliada, os referidos autores propõem o ensino de conceitos como meio para a compreensão de temas socialmente relevantes, bem como a discussão sobre a dinâmica de produção e apropriação do conhecimento científico- 
FORMAÇÃO REFLEXIVA DE PROFESSORES DE CIÊNCIAS...

tecnológico, o que supõe a superação de uma visão ingênua de C\&T, marcada pelos mitos já descritos no parágrafo anterior.

\section{A reflexão na formação de professores}

No campo de pesquisa da formação de professores de Ciências, existem diversos trabalhos (MOURA, 2013; BONZANINI; BASTOS, 2013, 2009; SILVA; DUARTE, 2009; DUARTE, et al., 2009; MARTINS; HIGA, 2009; ROSA-SILVA; LORENCINI JÚNIOR, 2007; LONGUINI; NARDI, 2004; DINIZ; CAMPOS, 2004; FREITAS, VILLANI, 2002; CAMPOS, DINIZ, 2001) que investigam e/ou discutem o uso da reflexão nos processos formativos, tanto inicial como continuada, indicando as possibilidades dessa abordagem. Nesse trabalho, ao buscar aproximações entre a formação reflexiva de professores e o enfoque CTS, intencionamos colaborar com essas discussões apresentando uma perspectiva teórica que possa subsidiar debates e práticas voltados mais diretamente para a formação reflexiva de professores de disciplinas relacionadas com as Ciências Naturais.

Slongo, Delizoicov e Rosset (2010), ao analisarem a produção acadêmica sobre formação de professores de Ciências Naturais, publicada nas atas do Encontro Nacional de Pesquisas em Educação em Ciências (ENPEC), identificaram uma predominância de trabalhos que convergiram para os conceitos de "professor pesquisador" e "professor reflexivo", o que indica uma tendência crescente na área de formação de professores de Ciências, desde os anos 2000. No entanto, as referidas autoras enfatizam a necessidade de se aprofundar nesses conceitos e das pesquisas trazerem de forma clara as concepções epistemológicas que embasam essas perspectivas. Da mesma forma, Martins e Higa (2009), ao revisar a produção específica sobre o uso conceito do professor reflexivo na formação de professores de Ciências, encontram alguns trabalhos que apenas citam o conceito como uma alternativa formativa, sem, no entanto, discutir o mesmo ou utilizá-lo na análise.

Os usos e abusos da reflexão como estratégia para a formação de professores são evidenciados ainda em diversos trabalhos (ZEICHNER, 2008, 1993; LIBÂNEO, 2002; PIMENTA, 2002; CONTRERAS, 2002), que alertam sobre os riscos da não definição de qual conceito de reflexão está sendo referido. Isto acaba por esvaziá-lo de sentido, ou pior, como adverte Contreras (2002), de subverter seu uso para a instrumentalização técnica. Assim, exploraremos brevemente a origem do conceito, algumas críticas à reflexão pautada pela racionalidade prática e as tradições do uso do termo. 
A origem do termo reflexivo é relacionada principalmente aos trabalhos de Jonh Dewey, em especial o seu livro How we think publicado em 1933 (ZEICHNER, 1993). Segundo Zeichner (1993), Dewey define a ação reflexiva como "uma consideração ativa, persistente e cuidadosa daquilo que se acredita ou que se pratica à luz dos motivos que o justificam e das consequências a que conduz" (p. 18). Essa se diferencia do ato de rotina, que é principalmente orientado pela tradição, impulso e autoridade. $\mathrm{O}$ ato de rotina reforça as ideologias dominantes, impedindo os professores de realizar grandes rupturas e experimentar opiniões alternativas.

De acordo com Pimenta (2002), é principalmente a partir dos estudos de Donald Schön que o conceito de professor reflexivo ganha popularidade, por meio de uma proposta de formação baseada na epistemologia da prática, que valoriza a prática profissional como forma de produção de conhecimento consolidada por meio da reflexão, análise e problematização. Segundo essa autora, o trabalho de Schön se dá por meio da crítica à formação a partir da racionalidade técnica, que esse autor julgava ser incapaz de dar conta da singularidade, incertezas, instabilidade e dilemas característicos do ensino. Pimenta (2002) defende a fecundidade das análises críticas iniciadas por Schön no desencadeamento de diversas pesquisas na área da formação de professores levando inclusive à discussão de temas ausentes em suas preocupações iniciais.

Ao criticar duramente a formação centrada na técnica, Schön (1992) defende a formação profissional baseada na epistemologia da prática, no aprender fazendo, observando e imitando os mais experientes. Isto porque para o referido autor, o conhecimento emerge no momento em que refletimos sobre a ação, o que favorece a percepção de comportamentos e uma reconstrução das intenções, estratégias e pressupostos utilizados pelos professores em suas práticas.

O movimento do "professor reflexivo" tem contribuído para a crítica à perspectiva técnica e a valorização da formação através da prática e da ação reflexiva. Porém, o entendimento da reflexão como um ato individual do professor, tendo, portanto, como objetivo a transformação da prática no contexto imediato e restrito, tem sido criticado por diversos autores (DUARTE, 2003; CONTRERAS, 2002; PIMENTA, 2002). Para a superação desse limite, seria importante considerar a reflexão como prática social, tendo em vista que se trata de um ato dialógico, valorizando a importância de que ela ocorra em grupo (ZEICHNER, 1993). 
Dadas às múltiplas interpretações em relação ao conceito de professor reflexivo e a fim de evitar noções equivocadas em relação aos objetivos e intencionalidades da formação reflexiva de professores, Zeichner (1993) se preocupa em estabelecer uma base conceitual para o tipo de reflexão que defende. Na tentativa de construir essa base, ele busca na literatura americana os diversos usos do termo reflexão, bem como as filosofias educacionais e sociais implícitas em cada uma dessas propostas. Assim, esse autor apresenta cinco tradições históricas da prática reflexiva no ensino e na formação de professores que serão brevemente descritas no quadro abaixo:

Quadro 2 - Tradições da Formação Reflexiva

\begin{tabular}{|c|l|}
\hline Tradição & \multicolumn{1}{c|}{ Descrição } \\
\hline Acadêmica & $\begin{array}{l}\text { Tem como base a reflexão sobre as disciplinas e a tradução do conhecimento } \\
\text { dessas para a compreensão do aluno. }\end{array}$ \\
\hline Eficiência Social & $\begin{array}{l}\text { Visa à aplicação de estratégias de ensino planejadas e sugeridas por } \\
\text { especialistas. Os saberes e capacidades que os professores precisam dominar } \\
\text { são especificados previamente. Essa abordagem é divida em dois segmentos: } \\
\text { técnico (treino de capacidades) e deliberativo (encorajam a participação dos } \\
\text { professores em investigações). }\end{array}$ \\
\hline Desenvolvimentista & $\begin{array}{l}\text { O professor reflete sobre seus alunos visando seus interesses, pensamento e } \\
\text { padrões de desenvolvimento. }\end{array}$ \\
\hline Reconstrução Social & $\begin{array}{l}\text { Preocupa-se com a reflexão sobre o contexto social e político e a busca de } \\
\text { transformação das práticas em prol da igualdade e da justiça. }\end{array}$ \\
\hline Genérica & $\begin{array}{l}\text { Ensino reflexivo é tomado como slogan, ou seja, sem que haja preocupação } \\
\text { com o conteúdo, critérios e formas de avaliação da reflexão. Considera-se } \\
\text { que as ações dos professores são melhores apenas por serem deliberadas ou } \\
\text { intencionais. }\end{array}$ \\
\hline
\end{tabular}

Fonte: Adaptado do texto de Zeichner (1993).

Se analisarmos cada uma dessas tradições, tomadas isoladamente, veremos que elas guardam relações entre diferentes modelos de formação de professores, comumente expressos na literatura da área por três abordagens diferentes: técnica, prática e crítica.

Os modelos fundamentados na racionalidade técnica centram-se na ideia de que “a prática profissional consiste na solução instrumental de problemas mediante a aplicação de um conhecimento teórico e técnico, previamente disponível, que procede da pesquisa científica" (CONTRERAS, 2002, p. 90). Já, os modelos orientados pela prática, consideram a ação educativa como um processo, que sendo fluida e instável não permite a sistematização proposta pela abordagem técnica. Assim, a abordagem prática propõe uma superação da técnica por meio da valorização do saber da prática em que o professor é produtor de conhecimento, por meio da reflexão e análise de seus atos (CHAPANI, 2010; CARR; KEMMIS, 2004; PIMENTA, 2002). Por fim, o modelo de 
racionalidade crítica, considera boa parte das ideias defendidas na abordagem prática, mas esse modelo se difere da prática em especial por acrescentar:

\begin{abstract}
a consciência de que as atividades educativas estão historicamente situadas; [...] que a educação constitui uma atividade social cujas consequências são sociais, não sendo só uma questão de desenvolvimento individual; [...] que a educação é intrinsecamente política, pois afeta as chances de vida dos envolvidos no processo [...] e por último a consciência de que o ato educacional (todo ato de ensino e cada oportunidade de aprendizagem incorporada a um currículo) é problemático em um sentido mais profundo que compreende a técnica e o ofício artesanal (CARR; KEMMIS, 2004, p. 39 , tradução nossa, itálicos do original).
\end{abstract}

Podemos notar, portanto, que as tradições de formação reflexiva apontadas por Zeichner (1993) estão fundamentadas em diferentes racionalidades.

A perspectiva acadêmica centra-se na preparação do saber disciplinar, dando ênfase à razão em detrimento da emoção e entendendo que o conhecimento do conteúdo, por parte do professor, se traduz por si só em capacidade de favorecer a compreensão desse pelo aluno. Essas características aproximam essa tradição do modelo de racionalidade técnica.

A tradição da eficiência social como aplicação técnica vai a contramão da origem do conceito de professor reflexivo proposto por Schön, ao basear-se justamente na racionalidade técnica tão criticada por esse autor (CONTRERAS, 2002). Já, a eficiência social na dimensão deliberativa, está vinculada ao incentivo para que os professores sejam ativos nas decisões e que investiguem suas práticas, o que permite associar essa tradição com a racionalidade prática. Assim também podemos entender a tradição desenvolvimentista cuja reflexão está voltada para o contexto interno da sala de aula.

A tradição da reconstrução social pode ser associada à perspectiva crítica, pois tem como intuito a inserção de questões de um contexto mais amplo (políticas, sociais) e vincula-se aos ideais de igualdade e justiça. Na figura 1 apresentamos uma síntese das relações que estabelecemos entre as racionalidades, que sustentam os modelos de formação, e as tradições reflexivas apontadas por Zeichner (1993). 


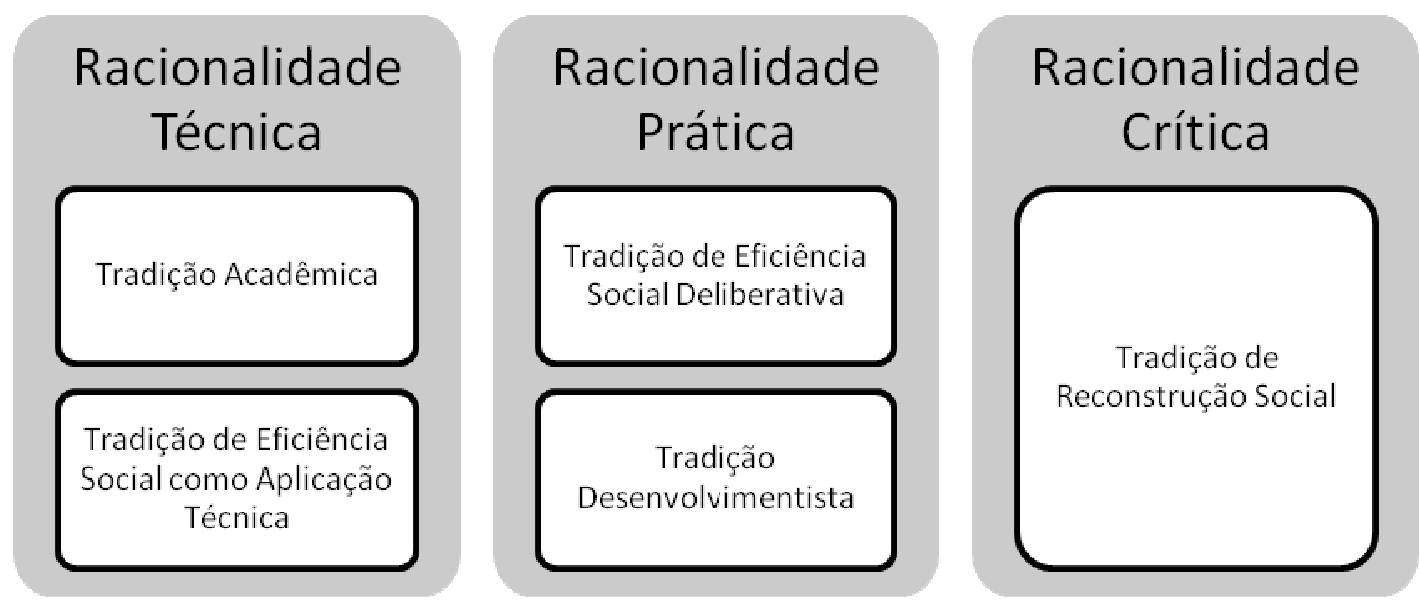

Figura 1 - Relações entre os modelos de racionalidade técnica e as tradições reflexivas.

Fonte: Elaboração das autoras. 2014.

Por fim, a tradição genérica não se associa a nenhum dos modelos, tendo em vista que por si só é vazia de conteúdo. Muitos trabalhos têm abordado a reflexão como alternativa para a formação de professores, sem aprofundar-se no conceito, tal como abordam Martins e Higa (2009), e poderiam ser relacionados a essa tradição. Zeichner (1993), ao defender seu posicionamento em relação à formação reflexiva de professores, busca articular sua opinião com as tradições apontadas (QUADRO 2), a fim de estabelecer o conteúdo e a qualidade da reflexão a que se refere. Entende que as abordagens acadêmicas e até mesmo a de eficiência social (desde que de caráter deliberativo) são importantes na medida em que trazem aportes da teoria e da prática respectivamente. Porém, é principalmente nas abordagens desenvolvimentista e de reconstrução social, que se centra para descrever as seguintes características que definem e orientam a prática reflexiva:

1. a reflexão volta-se tanto para prática quanto para questões externas, ou seja, seus estudantes e as condições sociais em que a prática está situada;

2. a formação reflexiva indica uma tendência democrática e emancipatória, ao considerar a importância das decisões dos professores e das dimensões sociais e políticas do ensino;

3. a reflexão é prática social, e portanto não individual, ela se faz tanto no compartilhar entre os professores e os conhecimentos produzidos pelas pesquisas desses, como pelo contato e pela apropriação crítica das pesquisas oriundas da academia.

É por meio dessas características que estabeleceremos algumas aproximações em relação à formação reflexiva e o enfoque CTS. 


\section{Aproximações entre Enfoque CTS e a formação reflexiva de professores}

No intuito de aproximar esses referenciais, abordaremos o enfoque CTS sobre a perspectiva ampliada e a reflexão tendo com ênfase, tanto a tradição desenvolvimentista como a de reconstrução social (ZEICHNER, 1993).

A justificativa para a escolha da perspectiva ampliada (AULER; DELIZOICOV, 2001) para abordagem do enfoque CTS na formação de professores fundamenta-se no fato dela favorecer, além da discussão de conteúdos científicos e tecnológicos, a reflexão sobre Ciências trazendo à tona influências sociais. Acreditamos, portanto, que essa é a abordagem que melhor se ajusta a nossa proposta, ou seja, a busca da formação reflexiva dos professores de Ciências, tal como defende Zeichner (1993).

Assim, por meio de nossa análise, estabelecemos quatro categorias para realizar as aproximações teóricas, a saber: i) Relevância das questões políticas e sociais; ii) Tendência democrática e emancipatória; iii) Prática social e iv) Relevância dos aspectos conceituais. A descrição dessas aproximações será apresentada de forma sintética no quadro 3:

Quadro 3- Aproximações entre Enfoque CTS e a formação reflexiva de professores

\begin{tabular}{|c|c|c|}
\hline $\begin{array}{c}\text { Aspectos } \\
\text { considerados } \\
\text { para as } \\
\text { aproximações }\end{array}$ & $\begin{array}{c}\text { Enfoque CTS } \\
\text { (perspectiva ampliada e crítica) }\end{array}$ & $\begin{array}{l}\text { Formação reflexiva } \\
\text { (desenvolvimentista e de } \\
\text { reconstrução social) }\end{array}$ \\
\hline $\begin{array}{l}\text { Relevância das } \\
\text { dimensões } \\
\text { sociais e } \\
\text { políticas }\end{array}$ & $\begin{array}{l}\text { Um dos objetivos centrais do enfoque CTS } \\
\text { é dar relevância às questões sociais que } \\
\text { permeiam a C\&T. A problematização da } \\
\text { realidade e dos valores da sociedade } \\
\text { moderna, bem como a orientação para o } \\
\text { comprometimento social e para análise } \\
\text { crítica dos modelos de desenvolvimento } \\
\text { econômico acentua a preocupação com a } \\
\text { dimensão política, social e consequências } \\
\text { ambientais das atividades científicas e } \\
\text { tecnológicas. }\end{array}$ & $\begin{array}{l}\text { Manifesta-se pela busca por } \\
\text { demonstrar que as alternativas de } \\
\text { ação refletem opções políticas que } \\
\text { devem ser examinadas, levando em } \\
\text { conta as condições sociais nas quais a } \\
\text { prática de ensino se situa, valorizando } \\
\text { o contexto externo à sala de aula e o } \\
\text { compromisso social na busca de } \\
\text { transformação das práticas em prol da } \\
\text { igualdade e da justiça. }\end{array}$ \\
\hline $\begin{array}{c}\text { Tendência } \\
\text { democrática e } \\
\text { emancipatória }\end{array}$ & $\begin{array}{l}\text { Estimula uma cultura de participação, } \\
\text { favorecendo a tomada de decisão e o } \\
\text { envolvimento ativo da sociedade nas } \\
\text { políticas científicas e tecnológicas em } \\
\text { oposição ao modelo tecnocrático, bem } \\
\text { como o desvelamento da realidade por } \\
\text { meio da superação de outros mitos } \\
\text { (salvacionismo e determinismo } \\
\text { tecnológico) relacionados à C\&T. }\end{array}$ & $\begin{array}{l}\text { Valorização da capacidade que os } \\
\text { professores têm de participar } \\
\text { ativamente das decisões que } \\
\text { envolvem o ensino, da formulação } \\
\text { dos propósitos e finalidades de seu } \\
\text { trabalho, bem como de produzir } \\
\text { conhecimento teórico enquanto } \\
\text { atuam. Isso envolve ainda atuar } \\
\text { contra situações de injustiça e } \\
\text { desigualdade que permeiam o ensino. }\end{array}$ \\
\hline $\begin{array}{l}\text { Relevância dos } \\
\text { aspectos } \\
\text { conceituais }\end{array}$ & $\begin{array}{l}\text { O ensino de conceitos é visto como meio } \\
\text { para a compreensão de temas socialmente } \\
\text { relevantes, não há redução de conteúdos, } \\
\text { mas ressignificação social dos mesmos. } \\
\text { Defende-se que a compreensão conceitual }\end{array}$ & $\begin{array}{l}\text { Orientada pela apropriação crítica de } \\
\text { teorias acadêmicas, porém com } \\
\text { entendimento de que a melhoria das } \\
\text { escolas não pode depender só dos } \\
\text { conhecimentos produzidos na }\end{array}$ \\
\hline
\end{tabular}




\begin{tabular}{|c|c|c|}
\hline & $\begin{array}{l}\text { da C\&T é imprescindível para a } \\
\text { participação social e a tomada de decisão. }\end{array}$ & $\begin{array}{l}\text { universidade, apesar de não } \\
\text { prescindir desses. }\end{array}$ \\
\hline Prática social & $\begin{array}{l}\text { A problematização das inter-relações CTS } \\
\text { orienta-se para a discussão coletiva de } \\
\text { conteúdos C\&T a partir de seus aspectos } \\
\text { sociais, políticos, culturais, ambientais, } \\
\text { econômicos, entre outros. A interatividade } \\
\text { e a reflexão crítica sobre situações reais e } \\
\text { existenciais para os estudantes são } \\
\text { estimuladas nessa abordagem. Por isso, é } \\
\text { comum no enfoque CTS o uso de } \\
\text { estratégias que reforcem a discussão } \\
\text { coletiva, como o trabalho em pequenos } \\
\text { grupos, resolução de situações problemas, } \\
\text { simulações, entre outros. }\end{array}$ & $\begin{array}{l}\text { A reflexão é prática social e como tal, } \\
\text { precisa ser realizada no coletivo, a } \\
\text { fim de que os professores apoiem e } \\
\text { sustentem o crescimento uns dos } \\
\text { outros, analisem e fortaleçam suas } \\
\text { crenças em conjunto. A interação } \\
\text { social favorece ainda a compreensão } \\
\text { de que os problemas da educação não } \\
\text { são apenas individuais, mas } \\
\text { estruturais, coletivos e amplos, } \\
\text { envolvendo questões econômicas, } \\
\text { políticas, éticas e históricas. }\end{array}$ \\
\hline
\end{tabular}

Fonte: Elaboração das autoras. 2014.

Observamos que os aspectos apresentados (QUADRO 3) são de extrema importância para a formação docente, em especial da área de Ciências, cujas transformações científicas e tecnológicas acabam por ser objeto direto de seu ensino. Dado o contexto atual, torna-se imprescindível não apenas a compreensão conceitual, mas também uma visão mais realista da natureza da C\&T, de como o conhecimento é social e historicamente construído, permeado por interesses e relações econômicas e políticas e não apenas voltado para o bem-estar social como propõe o mito salvacionista. A problematização dessa visão valoriza a necessidade em iniciar a partir do próprio professor, mas também junto aos seus alunos, uma cultura de participação da sociedade, tal como propõe Auler e Bazzo (2001), nas decisões que envolvam C\&T.

Segundo Auler (2002) a escola deve contribuir para a preparação da participação da sociedade, não apenas na apropriação dos produtos, mas nas definições do que será produzido. Nesse sentido concordamos com Santos (2005) quando defende que a construção de uma ideologia democrática, que favoreça espaços para que os cidadãos influenciem as decisões políticas que afetam suas vidas, demanda que os conhecimentos de e sobre Ciências sejam ancorados em perspectivas CTS eticamente orientadas.

Considerando a relevância da preparação para a participação social e a existência de diferentes compreensões vinculadas tanto às discussões do Movimento CTS, como às abordagens de ensino com Enfoque CTS, Strieder e Kawamura (2014) julgam importante sistematizar perspectivas de participação social. Para tanto, as autoras organizam essas perspectivas em cinco níveis crescente de crítica:

num primeiro nível encontra-se a perspectiva da informação (e não da tomada de decisão propriamente dita) que se dá pelo reconhecimento da presença da CT na sociedade. Num segundo nível, a participação ocorre num contexto micro, a partir de decisões de cunho mais individual, em geral 
relacionadas aos produtos da CT. No terceiro nível as decisões já envolvem o contexto macro, são coletivas e abarcam a discussão de problemas e impactos da CT na sociedade. No quarto nível, a participação se dá a partir do reconhecimento das contradições e por mecanismos de pressão. No quinto e último nível, a participação se dá no âmbito das esferas políticas, a partir da compreensão e discussão de políticas públicas. (STRIEDER; KAWAMURA, 2014, p. 108).

Ainda de acordo com as autoras supracitadas, é importante que essas diferentes perspectivas estejam presentes no ensino de Ciências, não de forma linear, mas em ciclos espirais para progressivo aprofundamento das temáticas a serem discutidas com os alunos (FIGURA 2).

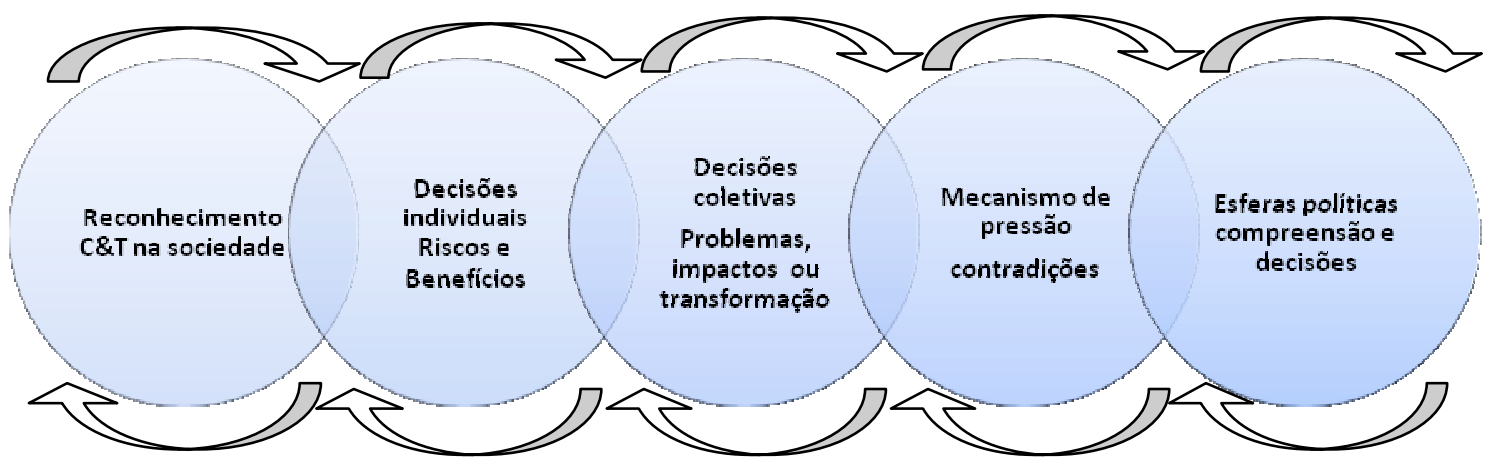

Figura 2 - Diferentes perspectivas de participação social em níveis crescente de crítica.

Fonte: Elaboração das autoras a partir das ideias de Strieder e Kawamura (2014).

Em se tratando da formação de professores de Ciências, consideramos a relevância de abrir espaços de discussão de temas, a partir de um enfoque CTS, que considere os diferentes níveis de participação social apontados por Strieder e Kawamura 2014, visando fomentar perspectivas mais críticas. Desta forma, acreditamos ser possível, favorecer a compreensão das possibilidades de participar das questões que envolvem C\&T e consequentemente uma visão mais realista dessas atividades entre os docentes e futuros docentes.

Vale salientar que todas as discussões acima são permeadas por valores vinculados aos interesses coletivos, como os de solidariedade, fraternidade, de consciência do compromisso social, de reciprocidade, de respeito ao próximo e de generosidade. Em se tratando do enfoque CTS, "tais valores se relacionam às necessidades humanas, em uma perspectiva de questionamento da ordem capitalista, na qual os valores econômicos se impõem aos demais" (SANTOS, 2007, sem página).

Assim, entendemos que as discussões a partir do enfoque CTS ampliado crítico fornecem à reflexão um conteúdo político e social, não se restringindo ao ensino de 
FORMAÇÃO REFLEXIVA DE PROFESSORES DE CIÊNCIAS...

Ciências ou ao contexto interno da sala de aula, mas também orientando os professores e futuros professores a "serem reflexivos sobre o seu ensino e sobre os contextos nos quais este se desenrola" (ZEICHNER, 1993, p. 50, itálico do original).

Identificamos ainda um potencial do enfoque CTS em fomentar, nas ações formativas de professores da área de Ciências, uma mudança epistemológica sobre a natureza do conhecimento e da Ciência, tal como discute Chapani (2010), dado que um dos objetivos desse movimento é justamente desvelar os mitos que permeiam a Ciência e a Tecnologia. Para tanto, julgamos indispensável agregar, nos currículos de formação de professores, estudos em filosofia, história e sociologia da ciência, a fim de contribuir para a reconstrução de uma imagem crítica de C\&T, que as considere como construção humana e cultural em evolução, levando em conta os valores, interesses e conflitos que envolvem as comunidades científicas e marcadamente influenciadas por certos contextos sociais (MARTÍNEZ; LOZANO, 2013).

\section{Considerações finais}

Neste trabalho buscamos relacionar o enfoque CTS e a formação reflexiva de professores. A diversidade de interpretações e usos desses referenciais nos encaminhou a uma descrição e análise das diferentes abordagens de cada temática. Em se tratando do

enfoque CTS, identificamos que nem sempre estão presentes nas abordagens a preocupação social e política, característica do movimento CTS desde a sua origem. Em se tratando do ensino reflexivo estabelecemos uma relação entre as tradições apresentadas por Zeichner (1993) e as racionalidades que orientam os modelos de formação de professores.

Ao embasar uma ação de formação reflexiva de professores nos pressupostos do enfoque CTS para o ensino de Ciências é preciso levar em conta as diferentes abordagens e tradições sintetizadas a fim de aliar adequadamente as ações aos objetivos formativos.

Nas aproximações que fizemos no presente trabalho consideramos o enfoque CTS no ensino de Ciências e a formação reflexiva de professores, numa perspectiva crítica. Assim, como resultados identificamos o alinhamento entre esses referencias no que se refere a: $i$ ) considerar o ensino e a aprendizagem de docentes como práticas sociais sustentadas por princípios ético-políticos que devem ser explicitados nos processos formativos; ii) considerar a ciência e a tecnologia como importantes formas de organização do pensamento e intervenção na sociedade e que, por isso, devem ser 
compreendidas de maneira crítica; iii) valorizar a democracia na sua expressão mais ampla; iv) tomar a educação como possibilidade de emancipação.

Entendemos que a abordagem crítica e ampliada das relações CTS pode contribuir para a formação reflexiva a partir da perspectiva desenvolvimentista e de reconstrução social, tanto por favorecer uma visão mais realista sobre a natureza da Ciência, como por fornecer conteúdo à reflexão por meio da contextualização (histórica, política, cultural, social, ambiental, ética e econômica) dos temas que envolvem C\&T.

Ressaltamos que trabalhar a partir dos pressupostos do enfoque CTS na formação de professores de Ciências pode possibilitar processos reflexivos que contemplem as especificidades formativas dessa área. Defendemos, portanto, a inserção de abordagens CTS críticas na formação inicial e continuada de professores de Ciências visando estimular a reflexão que "contribua para a construção de uma sociedade melhor para o filho de todos" (ZEICHNER, 2008, p. 545) e que busque avaliar as práticas na tentativa de promover diferença na vida dos alunos.

Como proposta prática para essa inserção, sugerimos que as disciplinas da formação inicial de professores de Ciências Naturais, considerem os pressupostos do enfoque CTS e possibilitem momentos de reflexão sobre o ensino, docência e as implicações sociais e ambientais da C\&T. O estágio supervisionado desenvolvido a partir dessas orientações pode favorecer a promoção de espaços coletivos de reflexão sobre a prática efetiva dos futuros docentes.

A formação continuada de professores também poderia ser organizada a partir dos referenciais do enfoque CTS e do professor reflexivo, envolvendo ainda a constituição de coletivos de professores de diferentes áreas, com a finalidade de desenvolver, em conjunto, estudos, elaboração, implementação e acompanhamento de propostas CTS em suas salas de aula. Em se tratando da formação continuada, consideramos a importância de institucionalização das iniciativas, a fim de favorecer condições para inserção e permanência dos professores nas ações formativas (BINATTO; DUARTE, 2014).

Ressaltamos, porém, que inserir o enfoque CTS em programas de formação reflexiva, não envolve apenas uma mudança curricular. Exige uma definição clara e explícita dos objetivos, justificativas e consequências das ações e crenças do próprio programa e ainda de seus formadores, seguida de uma análise ampla das condições sociais e políticas que permeiam o ensino e da problematização das condições de 
FORMAÇÃO REFLEXIVA DE PROFESSORES DE CIÊNCIAS...

trabalho e formação docente. Significa, ainda, estimular nos professores e futuros professores a compreensão da formação como um processo contínuo, que não se encerra ao término dos programas, mas que se prolonga no decorrer da prática profissional e se fortalece no convívio entre os pares.

\section{Referências}

ACEVEDO DÍAZ, J. A.; VÁZQUEZ ALONSO, A.; MANASSERO MAS, M. A. El movimiento ciencia-tecnología-sociedad y la enseñanza de las ciencias. In: MANASSERO MAS, M. A.; VÁZQUEZ ALONSO, A.; ACEVEDO DÍAZ, J. A. Avaluació dels temes de ciència, tecnologia i societat. Palma de Mallorca: Conselleria d'Educació i Cultura Del Govern de les Illes Ballears, 2001. Disponível em: $<$ http://www.oei.es/salactsi/acevedo13.htm>. Último acesso em: 20 dez. 2014.

AIKENHEAD, G. S. What is STS science teaching? In: SOLOMON, J.; AIKENHEAD, G. (Orgs.). STS education: international perspectives on reform. New York: Teachers College Press, 1994. p. 47-59.

AULER, D. Interações entre Ciência-Tecnologia-Sociedade no contexto da formação de professores de ciências. Tese de Doutorado em Educação - Centro de Ciências da Educação, Universidade Federal de Santa Catarina, Florianópolis, 2002.

AULER, D.; BAZZO, W. A . Reflexões para a implementação do movimento CTS no contexto educacional brasileiro. Ciência\& Educação, v. 7, n. 1, p. 1-13, 2001. Disponível em: <http://www.scielo.br/pdf/ciedu/v7n1/01.pdf>. Último acesso em 10 nov. 2014.

AULER, D.; DELIZOICOV, D. Alfabetização científico-tecnológica para quê? Ensaio: Pesquisa em Educação em Ciências, Belo Horizonte, v. 3, n. 1, p. 105-115, 2001. Disponível em: $<$ http://www.portal.fae.ufmg.br/seer/index.php/ensaio/article/viewFile/44/203>. Último acesso em 15 jan. 2015.

AZEVEDO, R. O. M.; GHEDIN, E.; FORSBERG, M. C. S.; GONZAGA, A. M. O enfoque CTS na formação de professores de Ciências e a abordagem de questões Sociocientíficas. In: ENCONTRO NACIONAL DE PESQUISA EM ENSINO DE CIÊNCIAS, 9., 2013. Águas de Lindóia. Atas... São Paulo: ABRAPEC, 2013.

BINATTO, P. F. ; DUARTE, A. C. S. Possibilidades e limites de uma ação formativa com professores de ciências em exercício a partir do enfoque ciência, tecnologia e sociedade. In: SEMINÁRIO INTERNACIONAL DA REDE ESTRADO, 10., 2014. Salvador. Anais ... Bahia: RED ESTRADO, 2014. CD-ROM.

BONZANINI, T. K.; BASTOS, F. Formação continuada de professores: algumas reflexões. In: ENCONTRO NACIONAL DE PESQUISA EM EDUCAÇÃO EM CIÊNCIAS, 7., 2009, Florianópolis. Anais... Belo Horizonte: ABRAPEC, 2009. 
Estratégias de formação continuada de professores: análise de uma experiência. Enseñanza de las Ciencias. v. extra, p. 448-453, 2013. Disponível em: $<$ http://congres.manners.es/congres_ciencia/gestio/creacioCD/cd/articulos/art_846.pdf> Último acesso em 14 dez. 2014.

CAMPOS, L. M. L.; DINIZ, R. E. S. D. A prática como fonte de aprendizagem e o saber da experiência: o que dizem professores de Ciências e de Biologia. Investigação em Ensino de Ciências. v. 6, n 1. 2001. Disponível em: $<$ http://www.if.ufrgs.br/ienci/artigos/Artigo_ID192/v6_n1_a2001.pdf $>$. Último acesso em 20 jan. 2015.

CARR, W.; KEMMIS, S. Becoming Critical: Education, Knowledge and Action Research. New York: Taylor \& Francis e-Library, 2004. 249 p.

CASSIANI, S.; LINSINGEN, I. V. Formação inicial de professores de Ciências: perspectiva discursiva na educação CTS. Revista Educar, Curitiba, s/v, n.34, p. 127147, 2009. Disponível em: <http://www.scielo.br/pdf/er/n34/08.pdf>. Acesso em 08 nov. 2014.

CHAPANI, D. T. Políticas públicas e história de formação de professores de Ciências: uma análise a partir da teoria social de Habermas. $2010.421 \mathrm{f}$. Tese de Doutorado em Educação para Ciência - Faculdade de Ciências, Universidade Estadual Paulista Júlio de Mesquita Filho, Bauru, 2010. Disponível em: $<$ http://www2.fc.unesp.br/BibliotecaVirtual/DetalhaDocumentoAction.do?idDocument $\underline{\mathrm{o}=294}$ >. Acesso em 05 fev. 2014.

CONTRERAS, J. A autonomia de professores. São Paulo: Cortez, 2002. 296 p.

DEMO, P. Educação Científica. In: B. Téc. Senac: a R. Educ. Prof., Rio de Janeiro, v. 36, n.1, jan./abr. 2010. Disponível em: <http://www.senac.br/BTS/361/artigo2.pdf>. Último acesso em: 24 jan. 2015.

DINIZ, R. E.S. CAMPOS, L. M. L. Formação inicial reflexiva de professores de ciências e biologia: possibilidades e limites de uma proposta. Revista Brasileira de Pesquisa em Educação em Ciências, v.4, n.2, 2004. Disponível em: <revistas.if.usp.br/rbpec/article/download/155/140>. Último acesso em: 24 jan. 2015.

DUARTE M. S.; SCHWARTZ L. B.; SILVA A. M. T. B.; REZENDE F. Perspectivas para além da Racionalidade Técnica na Formação de Professores das Ciências. In: ENCONTRO NACIONAL DE PESQUISA EM EDUCAÇÃO EM CIÊNCIAS, 7. 2009, Florianópolis. Anais... Belo Horizonte: ABRAPEC, 2009.

DUARTE, N. Conhecimento tácito e conhecimento escolar na formação do professor (por que Donald Schön não entendeu Luria). Educ. Soc., v. 24, n. 83, p. 601-625, agosto 2003. Disponível em: http://www.scielo.br/pdf/es/v24n83/a15v2483.pdf. Acesso em 18 dez. 2014.

FERRAZ, L. N. C. V. M. Metodologia do ensino das Ciências: concepção e avaliação de uma acção de formação contínua para professores numa perspectiva CTS. 2009. 
672f. Tese de Doutorado em Educação - Instituto de Educação e Psicologia, Universidade do Minho, Portugal, 2009.

FREITAS, D.; VILLANI, A. Formação de professores de ciências: um desafio sem limites. Investigações em Ensino de Ciências, Porto Alegre, v. 7, n. 3, 2002. Disponível em: <http://www.if.ufrgs.br/ienci/artigos/Artigo_ID90/v7_n3_a2002.pdf>. Último acesso em 16 dez. 2014.

GHEDIN, E. Professor reflexivo: da alienação da técnica à autonomia da crítica. In: PIMENTA, S. G.; GHERDIN, E. Professor reflexivo no Brasil: gênese e crítica de um conceito. 2. ed. São Paulo: Cortez, 2002.

FILHO, D. D. O. B.; MACIEL, M. D.; SEPINI, R. P.; ALONSO, Á. V. Alfabetização científica sob o enfoque da Ciência, Tecnologia e Sociedade: implicações para a formação inicial e continuada de professores. Revista Electrónica de Enseñanza de las Ciencias, v. 12, n. 2, p. 313-333, 2013. Disponível em: $<$ http://reec.uvigo.es/volumenes/volumen12/reec_12_2_5_ex649.pdf $>$. Último acesso em 15 fev. 2015.

LIBÂNEO, J. C. Reflexividade e formação de professores: outra oscilação do pensamento pedagógico brasileiro? In: PIMENTA, S. G.; GHERDIN, E. (Orgs.). Professor reflexivo no Brasil: gênese e crítica de um conceito. 2. ed. São Paulo: Cortez, 2002. p. 53-80.

LINSINGEN, I. Perspectiva educacional CTS: aspectos de um campo em consolidação na América Latina. Ciência \& Ensino, UNICAMP, v. 1, p. 01-16, 2007. Disponível em: $<$ http://prc.ifsp.edu.br/ojs/index.php/cienciaeensino/article/view/150/108>. Último acesso em: 24 fev. 2015.

LONGUINI, M.D.; NARDI, R. A prática reflexiva na formação inicial de professores de Física: análise de uma experiência. In: NARDI, R.; BASTOS, F; DINIZ, R. E. S; Pesquisas em ensino de ciências: contribuições para a formação de professores, v. 5, São Paulo: Escrituras, 2004.

LUJÁN LÓPEZ, J. L.; LÓPEZ CEREZO, J. A. Educación CTS enacción: Enseñanza secundaria y universidad. In: GONZÁLEZ GARCÍA, M. I.; LÓPEZ CEREZO, J. A.; LUJÁN LÓPEZ, J. L. (Orgs.). Ciencia, Tecnología y Sociedad: una introducción al estudio social de la ciencia y la tecnología. Madrid: Editorial Tecnos, 2000. p. 225-252.

MARTÍNEZ, L. P. F. A abordagem de questões sociocientíficas na formação continuada de professores de Ciências: contribuições e dificuldades. 2010. 351f. Tese de Doutorado em Educação para Ciência - Faculdade de Ciências, Universidade Estadual Paulista Júlio de Mesquita Filho, Bauru, 2010.

MARTÍNEZ, L. P. F.; LOZANO, D. L. P. La emergencia las cuestiones sociocientificas en el enfoque CTSA. Góndola, v. 8, n. 1, 2013. Disponível em: http://comunidad.udistrital.edu.co/geaf/files/2013/08/2013Vol8No1-003.pdf. Acesso em 11 dez. 2014. 
MARTINS, A. A.; HIGA, I. O professor reflexivo e a formação inicial de professores de Ciências: uma análise da produção recente. In: ENCONTRO NACIONAL DE PESQUISA EM ENSINO DE CIÊNCIAS, 7., 2009. Florianópolis. Atas... Santa Catarina: $\quad 2009 . \quad$ Disponível em: < http://www.nutes.ufrj.br/abrapec/vienpec/CR2/p1072.pdf>. Acesso em 25 nov. 2014.

MEGID NETO, J.; JACOBUCCI, D. F. C., E JACOBUCCI, G. B. Para onde vão os modelos de formação continuada de professores no campo da Educação em Ciências? Revista Horizontes, v. 25, n. 1, p. 73-85, 2007.

MOURA, R. M. Professor Reflexivo no Ensino de Ciências. In: OLIVEIRA, M. M. (Orgs.). Sequência didática interativa no processo de formação de professores. Petrópolis-RJ: Vozes, 2013.

OSORIO, C. La educación científica y tecnológica desde el enfoque en Ciencia, Tecnología y Sociedad: aproximaciones y experiencias para la educación secundaria. Revista Iberoamericana de educación, n. 28, p. 61-82, 2002.

PIMENTA, S. G. Professor Reflexivo: Construindo uma crítica. In: PIMENTA, S. G.; GHERDIN, E. (Orgs.). Professor reflexivo no Brasil: gênese e crítica de um conceito. 2. ed. São Paulo: Cortez, 2002. p. 17-52.

ROEHRIG, S. A. G.; CAMARGO, S. A educação com enfoque CTS no quadro das tendências de pesquisa em ensino de ciências: algumas reflexões sobre o contexto brasileiro atual. Revista Brasileira de Ensino de Ciência e Tecnologia, Ponta Grossa, v. 6, n. 2, p. 117-131, 2013.

Disponível em: <https://periodicos.utfpr.edu.br/rbect/article/view/1631/1039 >.Último acesso em 14 jan. 2015.

ROSA-SILVA, P. O.; LORENCINI JÚNIOR, Á. Análise das reflexões de uma professora de ciências do ensino fundamental sobre avaliação escolar. Estudos em Avaliação Educacional, v. 18, n. 38, p. 111-136, 2007. Disponível em: $<$ http://www.fcc.org.br/pesquisa/publicacoes/eae/arquivos/1400/1400.pdf $>$. Último acesso em: 24 fev. 2015.

SCHÖN, D. Formar Professores como Profissionais Reflexivos. In: Nóvoa, A. (Org.). Os professores e a sua formação. Lisboa: Publicações D. Quixote, 1992.

SANTOS, M. E. V. M. Cidadania, conhecimento, ciência e educação CTS. Rumo a "novas" dimensões epistemológicas. Revista Iberamericana de Ciência, Tecnologia y Sociedad - CTS, vol. 6, n. 2, p.137-157, 2005. Disponível em: $<$ http://www.scielo.org.ar/scielo.php?script=sci_arttext\&pid=S1850-

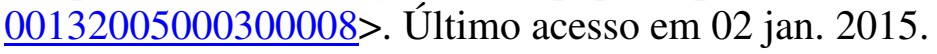

SANTOS, W. L. P. Contextualização no ensino de Ciências por meio de temas CTS em uma perspectiva crítica. Ciência e Ensino, Campinas, v. 1, n. especial, 2007.

Disponível

em:

$<$ http://prc.ifsp.edu.br/ojs/index.php/cienciaeensino/article/view/149/120>. Último acesso em 05 nov. 2014. 
FORMAÇÃO REFLEXIVA DE PROFESSORES DE CIÊNCIAS...

Educação CTS e cidadania confluências e diferenças. Amazônia Revista de Educação em Ciências e Matemáticas, Belém, v.9, n. 17, p. 49-62, 2012.

SANTOS, W. L. P.; AULER, D. (Orgs.). CTS e educação científica: desafios, tendências e resultados de pesquisa. Brasília: $\mathrm{Ed} \mathrm{UnB,} \mathrm{2011.} 460$ p.

SILVA, M. H. S.; DUARTE, M. C. O Diário de Aula na Formação de Professores Reflexivos: Resultados de uma Experiência com Professores Estagiários de Biologia/Geologia. Revista Brasileira de Pesquisa em Educação em Ciências, v. 01, n. 02, 2001.

SILVEIRA, R. M. C. F.; PINHEIRO, N. A. M.; BAZZO, W. A. A perspectiva social do desenvolvimento científico e tecnológico. Revista de Ensino de Engenharia, Brasília, v. 29, n. 1, p. 3-10, 2010. Disponível em: $<$ http://www.upf.br/seer/index.php/ree_old/article/view/262/1197>. Último acesso em 03 jan. 2015.

SLONGO, I. I. P.; DELIZOICOV, N. C.; ROSSET, J. M. A Formação de Professores Enunciada pela Pesquisa na Área de Educação em Ciências. ALEXANDRIA Revista de Educação em Ciência e Tecnologia, v. 3, n. 3, p. 97-121, 2010. Disponível em: $<$ http://alexandria.ppgect.ufsc.br/files/2012/03/ione.pdf>. Último acesso em $15 \mathrm{dez}$. 2014.

SOARES, M. N. O estágio curricular supervisionado na licenciatura em Ciências biológicas e a busca pela experiência formativa: aproximações e desafios. 2012. 262 f. Tese de Doutorado em Educação para Ciência - Faculdade de Ciências, Universidade Estadual Paulista Júlio de Mesquita Filho, Bauru, 2012. Disponível em : http://www2.fc.unesp.br/BibliotecaVirtual/DetalhaDocumentoAction.do?idDocumento $=543$. Último acesso em 20 jan. 2015 .

STRIEDER, R. Abordagem CTS e Ensino Médio: Espaços de articulação. 2008. 236 f. Dissertação de Mestrado em Ensino de Ciências - Faculdade de Educação, Universidade de São Paulo, São Paulo, 2008. Disponível em: http://www.teses.usp.br/teses/disponiveis/81/81131/tde-01072013-135158/pt-br.php.

Último acesso em 20 jan. 2015.

- Abordagens CTS na educação científica no Brasil: sentidos e perspectivas. 2012. 282 f. Tese de Doutorado em Ciências - Faculdade de Educação, Universidade de São Paulo, São Paulo, 2012. Disponível em: http://www.teses.usp.br/teses/disponiveis/81/81131/tde-13062012-112417/pt-br.php.

Acesso em 30 dez. 2014.

STRIEDER, R; KAWAMURA, M. R. D. Perspectivas de participação social no âmbito da educação CTS. Revista Uni-pluri/versidad, Colômbia, v.14, n.2, 2014. Disponível em:

http://aprendeenlinea.udea.edu.co/revistas/index.php/unip/article/view/20061/16951.

Último acesso em 05 dez. 2014. 
TEIXEIRA, P. M. M. A Educação Científica sob a perspectiva da Pedagogia HistóricoCrítica e do movimento CTS no ensino de Ciências. Ciência \& Educação, Bauru, v. 9, n. 2, p. 177-190, 2003. Disponível em: <http://www.scielo.br/pdf/ciedu/v9n2/03.pdf> Último acesso em 10 dez. 2014.

ZEICHNER, K. M. A Formação Reflexiva de Professores: Ideias e Práticas. Lisboa: Educa, 1993.

Uma análise crítica sobre a "reflexão" como conceito estruturante na formação docente. Educação \& Sociedade, Campinas, v. 29, n. 103, p. 535-554, 2008. Disponível em: <http://www.scielo.br/pdf/es/v29n103/12.pdf>. Último acesso em 15 jan. 2015.

PRISCILA FRANCO BINATTO. Licenciada em Ciências Biológicas pelo Centro Universitário do Leste de Minas Gerais (2003) e especialista em Ensino de Ciências por Investigação pela Universidade Federal de Minas Gerais (2012). Atualmente cursa o mestrado em Ciências e Matemática do Programa de Pós-graduação em Educação Científica e Formação de Professores da Universidade Estadual do Sudoeste da Bahia (UESB) e é professora do Instituto Federal do Norte de Minas Gerais (IFNMG). Tem experiência em ensino de ciências com enfoque CTS, formação de professores e ensino por investigação.

DAISI TERESINHA CHAPANI. Doutora em Educação para Ciências pela UNESP de Bauru. Professora adjunta do Departamento de Ciências Biológicas e do Programa de Pós-Graduação em Educação Científica e Formação de Professores da Universidade Estadual do Sudoeste da Bahia. Líder do Grupo de Estudos e Pesquisa em Formação e Atuação de Professores de Ciências. Tem experiência na área de Educação, com ênfase em Políticas Públicas. Desenvolve ações de ensino, pesquisa e extensão relacionadas principalmente à formação de professores de Ciências.

ANA CRISTINA SANTOS DUARTE. Graduada em Ciências com Habilitação em Biologia pela Universidade Estadual do Sudoeste da Bahia (1990), Mestre em Educação pela Universidade Federal da Bahia (1999), Doutora em Educação pela Universidade Federal da Bahia (2004) e Pós-Doutora em Didática das Ciências Experimentais pela Universidad Nacional del Litoral - Argentina (2013). Atualmente é professora Titular do Departamento de Ciências Biológicas da Universidade Estadual do Sudoeste da Bahia (UESB), da área Educação e Prática de Ensino. Tem experiência na área de Educação, com ênfase em Formação de Professores, atuando principalmente nos seguintes temas: ensino de Ciências e Biologia; educação inclusiva; aprendizagem; educação; diversidade. Docente, pesquisadora do Programa de Pós-Graduação em Educação Científica e Formação de Professores (DCB/UESB) e do Programa de PósGraduação em Enfermagem e Saúde (DS/UESB). Desenvolve e Coordena Projetos de Pesquisa e Extensão na área de Educação voltados para a formação de professores e o processo ensino-aprendizagem de Ciências e Biologia.

Recebido: 18 de julho de 2014

Revisado: 03 de janeiro de 2015

Aceito: 24 de fevereiro de 2015 